\title{
Investigating the Scale of the Problem of Children in Residential Care in the UK Being Exploited by External Agents for Sexual Purposes
}

\author{
Richard Barker ${ }^{1} \&$ Maurice Place ${ }^{2}$ \\ ${ }^{1}$ Emeritus Professor of Child Welfare, Northumbria University, Coach Lane Campus, Newcastle upon Tyne, UK \\ ${ }^{2}$ Visiting Professor of Child \& Adolescent Psychiatry, Northumbria University, Coach Lane Campus, Newcastle \\ upon Tyne, UK \\ Correspondence: Maurice Place, Visiting Professor of Child \& Adolescent Psychiatry, Northumbria University, \\ Coach Lane Campus, Newcastle upon Tyne, NE7 7XA, UK. E-mail: maurice.place@ northumbria.ac.uk
}

Received: January 31, 2013 Accepted: March 7, 2013 Available online: March 22, 2013

doi:10.11114/ijsss.v1i1.109 URL: http://dx.doi.org/10.11114/ijsss.v1i1.109

\begin{abstract}
This research is an exploratory study of the potential problem of children and young people in residential care being groomed and sexually exploited and abused by people from outside care without the involvement of care staff. A postal questionnaire was sent to all Chairs of English Local Safeguarding Children's Boards (LSCBs). 38 responses were received, covering a range of types of local areas. $40 \%$ of respondents reported cases of this problem, $9.4 \%$ in relation to asylum seeking children. $17.1 \%$ recorded more than 15 cases in the previous 2 years. Respondents were split almost equally with regard to whether the current law was adequate to deal with this problem or not. Only 3\% of LSCB areas felt this was a declining problem. LSCBs felt that the most available existing resource to deal with the problem was professional knowledge, and the least was available physical resources. Given the size of the sample caution needs to be exercised in generalising from these results, but it seems that further investigation of this area would be helpful to aid the development and improvement of child protection services.
\end{abstract}

Keywords: child abuse, residential care, external perpetrators, LSCBs

\section{Introduction}

It is well recognised that children and young people who are in care are potentially vulnerable to exploitation. In particular there have been a growing number of reports about children in residential care who have been sexually exploited and abused by those who have direct responsibility for their 'care', or by others with the knowledge, and sometimes involvement, of the residential staff (e.g. Gil, 1982; Bibby, 1996; Corby, Doig, and Roberts, 2001; Barter, 2003; Department for Children, Schools and Families, 2010).

More recently however, there has been a developing concern that there is a problem that children and young people who are in care - particularly but not exclusively in residential care - are at risk of being groomed, procured and sexually exploited and abused by abusers from outside care without the involvement and indeed often despite the best prevention efforts of care staff. (Office of the Children's Commissioner, 2012a). It is clear then that there is a growing concern about this area of human activity and the vulnerability of children and young people. However, it is also clear that despite the recent concern there is still relatively little literature on this specific area of abuse, and the scale of the problem it presents.

Biehal and Wade (2000), carrying out one of the few studies that referred to this issue noted that children who go missing in England from care (three- fifths for periods of 24 hours or less) said that:

at considerable risk of sexual assault and sexual exploitation, including prostitution, whilst absent. The majority of those interviewed who had a history of prostitution had been coerced or enticed into it following their admission to residential care, either through other young people or procurers who targeted children's homes (p.217).

Although this issue is not addressed directly in the latest edition of statutory government guidance, it is implied in the "non - statutory practice guidance' section of "Working Together" which refers (presumably) to the abuse of children in care (Department for Children, Schools and Families, 2010) by stating that "previous high profile 
inquiries and reports into abuse of children living away from home have raised awareness of the particular vulnerability of these children" (p.292), before going on to underline the necessity that "staff and carers are alert to the risks of harm to children in the external environment from people prepared to exploit the additional vulnerability of children living away from home" (p.294).

The historic abuse of some female children and young people in this position has been highlighted by Coy (2009) in her survey of the literature on young women and care, who suggested that "young women who are currently looked after or have backgrounds of local authority care are significantly over- represented in prostitution in most major cities...similar findings are reported in Norway, Canada, and Australia” (p.255).

In addition, there has also been recent concern, and evidence, that trafficked children may be at particular risk of entering care and then being subsequently abused this way. One study that looked at the issues relating to agencies and trafficked children across three regions of England (EPCAT, 2007) found that:

Of the 80 children identified throughout this study as known or suspected victims of trafficking, the majority originated from Africa and East Asia with only three reports of children from Russia and Eastern Europe. China (30) and Nigeria (15) figured prominently with other children coming from Somalia (9), Vietnam (4), Eritrea (3), Bangladesh (3), Democratic Republic of the Congo(2), Burundi (2), Benin(2), Uganda(1), Togo (1), Cameroon (1), Liberia (1), Kosovo/Albania (1), Moldova (1), Russia(1) and 3 unknown. Participants in the study registered high levels of concern, but no conclusive evidence, about a 'significant' number of children from Afghanistan, India and Pakistan who may have been trafficked for labour exploitation or who may have become victims of labour exploitation after arrival in the UK. Without further information we are unable to include these cases in the final figures. However, the concerns around these children require much more investigation. Across the three regions, social services and other statutory agencies identified concern about child trafficking for sexual exploitation, domestic servitude, benefit fraud, labour exploitation in 'cannabis factories', manual labour, and for under-age forced marriage. Although patterns varied from one region to another, child trafficking for sexual exploitation appears in reports across all three regions (p.7).

Recent government guidance in the UK (Department for Children, Schools and Families, 2007), has sought to respond to this and echoes the concern that "Children who have been trafficked may be sexually abused as part of being controlled or because they are vulnerable. In many cases sexual exploitation is the purpose of the trafficking" (p.15).

It has been suggested that unaccompanied asylum seeking children may be particularly vulnerable to being targeted in relation to this form of abuse - whilst the evidence, including numbers, is difficult to obtain a recent parliamentary inquiry (House of Commons, 2009) noted that

we are alarmed by accounts given by our witnesses and reinforced by anecdotal evidence of traffickers training children to present themselves as unaccompanied asylum seekers in order to be placed in insecure care, often near the port of entry, which the trafficker can persuade or coerce them to leave. In effect, traffickers may be using the care home system for vulnerable children as holding pens for their victims until they are ready to pick them up (p.58).

It seems therefore that there is a range of possible dimensions to this area including

1) UK resident children and young people who are in residential care and are targeted and exploited by external agents for sexual purposes

2) UK resident children and young people who may be sexually abused prior to entering residential care and who continue to be abused by the same or other agents whilst they are in care

3) Non UK resident children (including asylum seeking children and trafficked children) who enter the UK, enter residential care, and are then sexually abused by external agents.

As information about this area is patchy and often anecdotal, the intention of this research was to try to obtain a more detailed picture of the size of the problem of this problem, and indeed to clarify if it was a problem. To achieve this we sought the views of all the English Local Safeguarding Children's Boards (LSCBs), which are the statutory bodies established under the Children Act 2004, and which have the responsibility for co-ordinating and ensuring the effectiveness of the work of partner bodies to safeguard and promote the welfare of children.

\section{Methodology}

A postal questionnaire was devised based upon a reading of the child protection literature and some of the issues 
that appeared to be of potential relevance from the published cases. The resulting questionnaire was then piloted with a small number of very experienced children's services and related agency professionals, and their feedback received and incorporated in relation to scope, ease of use and intelligibility. Using the strategies recommended to improve questionnaire return (Edwards, Roberts, Clarke, Diguiseppi, Wentz, et al., 2009), the revised questionnaire and a letter of introduction and explanation about the research were then sent to all the Chairs of the LSCBs in England in 2009. The chairs' names and addresses were publically available via the relevant government department website. University ethical approval was sought and obtained for this research. A copy of the final questionnaire is presented as Figure 1.

\section{GCS Questionnaire}

The statements below relate to issues that appear relevant to the issue of children in residential care being exploited for sexual purposes by external agents. If the data is difficult to obtain then we would be grateful if you would make an estimate based upon your professional judgement and experience.

1. Has this issue been one that has been discussed at the LSCB

Yes / No

If YES, was this in relation to policy issues/ specific cases / both

2. Is such grooming/procuring a problem in your area?

3. If so, how many suspected cases have there been in the last 2 years?

$0,1-5,6-10,11-15,>15$.

4. How many actual cases have there been in the last 2 years?

$0,1-5,6-10,11-15,>15$.

5. Were the cases mainly

boys / girls / both

6. In your view is this problem increasing / decreasing / remaining the same

7. Is it a particular problem with unaccompanied asylum seekers in your area?

Yes/No

8. Is this grooming/procuring difficult for the services to deal with?

9. Does the law provide adequate recourse?

10. If not, what are the particular problems?

11. Do the agencies involved agree how such cases should be handled?

If $\mathrm{NO}$ - which agencies disagree most commonly?

12. In dealing with these cases, do your services have sufficient

$$
\begin{aligned}
& \text { - financial support } \\
& \text { - professional knowledge } \\
& \text { - professional training } \\
& \text { - physical resources }
\end{aligned}
$$$$
\text { Yes / No }
$$$$
\text { Yes / NO }
$$

Other issues

13. Is there anything else/significant about this area you would like to comment on?

Thank you very much for your help and cooperation with this survey. 
The questionnaire asked for information about the problem in relation to that particular LSCB area. Whilst the information sought was general, if specific information relating to individuals was mentioned then we asked that it be anonymised by the chairs of the boards.

A total of 146 questionnaires were sent, and then after a 10 week period, a follow up letter and repeat questionnaire was sent. In total we had 38 responses. Interestingly, there were 7 questionnaires that were returned as "not known at this address " - even thought the address was that which was listed as the correct one on the relevant government website. This raises the question as to whether all correspondence from government was getting to all chairs of LSCB's. In most cases, we were able to obtain the correct address by searching the relevant websites for the information, although in the cases of 2 local authorities, despite our best efforts, including direct contact with the relevant children's services section, it proved impossible to determine the contact details of the chairs of the LSCBs as the respondents did not know and could not access the relevant information.

The responses, although representing a minority of LSCBs, were received from a wide sample that covered urban and rural areas spread across the whole of England, including areas with large mixed race populations. The returns also included London boroughs and LSCB areas that contained points of entry into the UK such as airports and seaports. Thus there is the possibility, whilst our sample was limited, that the picture the questionnaires presented was broadly indicative of the national position, although caution needs to be exercised in relation to drawing this conclusion.

\section{Findings}

Overall, $40 \%$ of LSCB respondents said that children in residential care being procured by those outside residential care, without the involvement of the care staff, for sexual purposes was a child protection problem for them.

We were interested to know if the issue had been discussed by the LSCBs, and $66 \%$ of the sample said that it had and $34 \%$ that it had not. (subsequent statistics refer to the whole of the sample of respondents unless otherwise indicated). In relation to unaccompanied asylum seeking children, responses indicated that only $9.4 \%$ of LSCBs who completed returns reported that it was a problem in relation to these children, a lower figure than might have been expected given the Home Office Select Committee Report (House of Commons, 2009).

With regard to the suspected and actual incidence of cases of procuring children in residential care in the previous 2 years, Table 1 indicates that whilst a sizeable minority reported no suspected cases, the majority of LSCB respondents reported at least 1 case, with one in seven reporting more that 15 suspected cases.

Table 1. Number of suspected cases of procuring children from residential care by external agents in the previous two years.

\begin{tabular}{llllll}
\hline & None & $1-5$ & $6-10$ & $11-15$ & Over 15 \\
\hline Number of suspected cases in indiv LSCBs (\%) & 22.9 & 45.7 & 14.3 & 2.9 & 14.3 \\
\hline
\end{tabular}

In relation to actual cases recorded, Table 2 indicates a similar position to suspected cases, albeit with an even higher percentage of LSCBs reporting 15 or more actual cases of procuring in the previous two years.

Table 2. Number of cases of procuring children from residential care by external agents in the previous two years.

\begin{tabular}{llllll}
\hline & None & $1-5$ & $6-10$ & $11-15$ & Over 15 \\
\hline Number of cases in indiv LSCBs (\%) & 28.6 & 48.6 & 0 & 5.7 & 17.1 \\
\hline
\end{tabular}

In relation to actual and suspected cases, the overwhelming majority related to girls (88.5\%), followed by cases involving girls and boys ( $8.6 \%)$, with boy's only cases being the least prevalent $(2.9 \%)$.

How far does this seem to be a problem that is changing in terms of its extent? $42.5 \%$ of LSCBs judged that the problem was increasing in their area. 54.5\% indicated that it was remaining at the same level, and only $3 \%$ of LSCBs felt that it was a decreasing problem. 
Respondents were divided as to whether or not the law was adequate in regard to dealing with the problems thrown up by this child protection issue. $54.3 \%$ were of the opinion that it was, and $45.7 \%$ that it was not. There was a high level of agreement within individual LSCB areas about the adequacy or inadequacy of the law for dealing with this problem, with $90.3 \%$ saying there was agreement, and only $9.7 \%$ reporting disagreement.

Table 3. Availability of resources to deal with the problem

\begin{tabular}{lccc}
\hline Availability in LSCB Area of & sufficient resources & Yes & No \\
\hline Financial Resources & $51.9 \%$ & $48.1 \%$ \\
Professional Knowledge & $64.5 \%$ & $35.5 \%$ \\
Professional Training & $56.7 \%$ & $43.3 \%$ \\
Physical Resources & $42.9 \%$ & $52.7 \%$ \\
\hline
\end{tabular}

With regard to the issues of resources to respond to such events (Table 3), the LSCBs felt that the most available resource to deal with this problem was professional knowledge, and the least available physical resources.

\section{Discussion}

This survey sought to clarify the scale of the problem presented by the procurement of children in care for sexual exploitation. The responses did suggest that for some areas this is a major problem, and that certain LSCB's are gaining significant expertise in this area as a consequence.

Our findings showed that two-thirds of the sample of respondents had discussed the issue. It is perhaps surprising that at the time of our survey not all LSCBs have discussed this area in relation to the potential for the work of child protection agencies, even in those areas where it is perceived it has not been a problem. It may now be that following the publicity surrounding the Derby cases more LSCBs have discussed this potential area of activity.

The findings showed that this type of abuse of children and young people was a problem in 40\% of LSCB areas. It is possible that this figure under represents the extent of the problem, which, by its nature, is often secretive and hard to detect. What is not clear is whether the LSCB areas where respondents said they do not have a problem preventing the occurrence of this child protection problem or missing it? If the former, it may be that there are some areas which do not experience this problem because of good preventative policies and practices, and this needs further investigation. If the latter, then policies and procedures need to be devised to capture information about potential cases that are currently being missed.

A number of other issues were highlighted by the responses from the Chairs of the LSCBs. It is not clear what might the reasons be for the large differences in occurrence between areas? In part, this could simply be a reflection of the relative number of children in residential care within different areas - in some areas residential child care is not available or only used in respect of a tiny percentage of children in care.

It is also the case that this survey focussed on children in residential care, as this was anecdotally reported as being a key area. However, the majority of children in care are in foster care - is there also a problem for children in foster care being procured by those outside foster care for sexual purposes, without the involvement of the foster carers? Our results showed variation between local areas in relation to their ability to respond to this problem. Further research is necessary to begin to ascertain why some LSCB areas that report finding the problem of children in residential care being procured by those outside residential care, without the involvement of the care staff, for sexual purposes find the problem more difficult to deal with than others?

Our survey indicated that some LSCB areas find the law adequate yet others areas inadequate in responding to this problem, this may be to do with different interpretations or understandings of the law in respect of the problem, or differences in the nature and extent of the problems with which different areas are having to deal? The figure of $9.4 \%$ of areas reporting this as being a problem in relation to asylum seeking children is lower than might have been expected based upon the EPCAT study quoted earlier (EPCAT, 2007). The recent publication by the National Institute of Clinical Excellence (NICE) (2010) on promoting the quality of care for looked after children and young people only refers to a danger of sexual explotation for such children, talking about the "need to address (asylum seeking children's) exceptional health and well being needs including post - traumatic stress, dislocation from country, family, culture language and religion (and) risk of sexual exploitation" (p.26). 
None of our respondents highlighted issues to do with Asian male predators and abuse - we did not specifically ask about this, and future research would be helpful to explore how far this is indeed and issue and in what ways.

Is the problem of children in residential care being exploited by external agents for sexual purposes a problem that is confined to England, or is it more widespread, and how far does the asylum seeking dimension resonate with other countries? Anecdotal evidence following an international conference presentation of these preliminary results (Barker and Place, 2010) indicated that professionals from other countries in Europe, North America and Australasia felt there may be a similar problem in their countries.

What are the implications for services of only $3 \%$ of respondents believing the problem of children in residential care being exploited by external agents for sexual purposes is decreasing? The Coalition Government's Comprehensive Spending Review of October 2010 set out its plans for public spending plans until 2015, over five years the plan is to cut public spending by $£ 81$ billion pounds. Certain areas are said to be protected, the Department of Education budget is to be raised in real terms by $0.1 \%$ per annum, Health Service funding by $0.4 \%$ per annum. However, most commentators believe that in effect there will be real cuts to all budgets in practice, and most estimates are that at least 100,000 public service jobs will be lost each year. Maurice Bates, interim Co-Chair of the College of Social Work (Community Care 2010), said that councils faced cuts of 7\% per annum and "any cuts will put pressure not only on the already stretched local authority social work teams, but also on the voluntary and private sector providers of social work services" (p.4).

Thus, the implication is that 'new' areas of child protection challenge such as this will have to be responded to in a climate of dwindling resources.

\section{More Recent Cases}

The problem of children in residential care being exploited by external agents for sexual purposes has recently received high profile attention in the popular media as a result of the criminal convictions in the Derby case and other areas (Derby LSCB, 2010; Rochdale LSCB, 2012). In Derby, a number of men were imprisoned for procuring and sexually abusing vulnerable girls, two of who either were or had been in care. The LSCB reported (Derby LSCB 2010):

The two young people were known to agencies, and there had been concerns about their welfare over a number of years. However despite these concerns they were seriously abused both before, and subsequent to being looked after by the local authority. Individual agencies had sought to offer specific support, but did not recognise the signs and symptoms of abuse evident in the behaviour of both young women and information was not shared effectively. Therefore the full picture of the young women's circumstances was not understood (p.5).

Subsequently, there has been a media furore about such cases, in part sparked by the suggestion that men of asian origin targeted vulnerable girls (The Guardian, 2011a). One commentator (The Observer, 2011) suggested that "of course such victims are targeted. However, far more significant than colour is the fact that many of them are in care and, therefore, more vulnerable generally" (p.15).

These comments were supported by the Head of Child Exploitation and Online Protection Centre (CEOP), (The Guardian, 2011b):

the sexual exploitation of children cannot "be simplified along ethnic lines", the head of the Child Protection Agency said today. Peter Davies was announcing that the Child Exploitation and Online Protection (CEOP) centre is to investigate "on-street" grooming, leading to abuse and exploitation (p.18).

This potential dimension of this problem was not one which we asked specific questions about in our research. Accordingly, the only conclusion we can draw from our data is that the issue of race and predators as a potential or actual problem was not one which was raised by any of our correspondents in their responses, and some of our respondents were from areas with large minority ethnic populations.

\section{Conclusion}

The results from this survey appear to confirm that there is a problem of children in residential care being procured by those outside residential care, without the involvement of the care staff, for sexual purposes. However, there appear to be great variations within the country including - between areas which perceive that there is an problem in their locality and areas which do not; between areas which have to deal with a relatively high number of cases and areas which do not; between areas which perceive that they can deal with the problem and areas which do not; between areas which feel they have adequate professional and physical resources and 
areas which do not.

The statistical results from the questionnaire were supported and illuminated by written comments from respondents who responded to the survey including:

"This is a new area of work which is throwing up numerous challenges and finance remains unclear at the moment."

"There are some professionals in some agencies with sufficient knowledge currently but this can vary dramatically with staff changes. Hence, a rolling programme of training is required"

"We have been able to respond appropriately to date but have low numbers so yet to be challenged"

"We respond through 'standard' Child Protection processes - but we need specialist' skills and services"

Our research indicated that there is almost universal agreement that this is not a problem which is likely to diminish in the future. Since this data was collected there has been an increased concern in the UK about the sexual exploitation of children, (Barnardo's, 2011; CEOP, 2011; Department of Education, 2011) and the Office of the Children's Commissioner (England) has produced an interim report from its inquiry the problem of sexual exploitation in gangs and groups. (Office of Children's Commissioner, 2012b). This fuller interim report followed an earlier accelerated report in July 2012, which showed that a disproportionate number of children who are sexually exploited were living in residential care, and that some residential children's homes (Office of Children's Commissioner, 2012a) "have been targeted by those who want to sexually exploit children". (p.40).

It seems clear then that there is substantiation that the information from our exploratory study indicates that concern about this subject is not misplaced. However, in relation to the practice on the ground in responding to this concern, here do appear to be some areas and authorities that are more successfully responding to these problems than others. Thus alongside further investigation of the problem there is the opportunity for further research into responses, and for good practice, policy and training lessons to be learnt and disseminated from these areas.

\section{Acknowledgments}

We are grateful for all the anonymous respondents who completed and returned our questionnaires in the midst of no doubt extremely busy and demanding professional lives.

\section{References}

Barker, R., \& Place, M. (2010). A research study of the extent of responses to children in residential care being procured and sexually abused by people in the wider community $11^{\text {th }}$ Biennial EUSARF Congress, Groningen, Holland, 24.9.2010.

Barnardo's. (2011). Puppet on a String. Essex: Barnardo's. http://www.barnardos.org.uk/ctf_puppetonastring_report_final.pdf

Barter, C. (2003). Abuse of Children in Residential Care. London: NSPCC. http://www.nspcc.org.uk/inform/research/briefings/abuseofchildreninresidentialcare_wda48221.html.

Biehal, N., \& Wade, J. (2000). Going missing from residential and foster care - living biographies and contexts. British Journal of Social Work, 30, 211-225. http://dx.doi.org/10.1093/bjsw/30.2.211

Bibby, P. C. (1996). Organised Abuse - the current debate. Aldershot: Arena.

Child Exploitation and Online Protection Centre - CEOP. (2011). Out of Sight, Out of Mind. London: CEOP. http://www.ceop.police.uk/Documents/ceopdocs/ceop_thematic_assessment_executive_summary.pdf

Childrens' Commissioner, Office of. (2012a). Briefing for the Rt Hon Michael Gove, MP secretary of State for Education, on the emerging findings of the OCC's Inquiry into Child Sexual Exploitation in Gangs and Groups, with a special focus on children in care. London: Office of the Childrens Commissioner. http://www.childrenscommissioner.gov.uk/content/publications/content_580

Childrens' Commissioner, Office of. (2012b) I thought I was the only one. The only one in the world - Interim Report on the Children's Commissioner Inquiry into Child sexual exploitation in Gangs and Groups. London: Office of the Childrens' Commissioner.

http://www.childrenscommissioner.gov.uk/content/publications/content_636

Corby, B., Doig, A., \& Roberts, V. (2001). Public Inquiries into Abuse of Children in Residential Care. London: Joseph Rowntree Foundation. 
Coy, M. (2009). Moved around like bags of rubbish nobody wants: how multiple placement moves can make young women vulnerable to sexual exploitation. Child Abuse Review, 18, 254-266. http://dx.doi.org/10.1002/car.1064

Department for Children, Schools and Families. (2007). Working Together to Safeguard Children who may have been trafficked. London: Department for Children, Schools and Families. https://www.education.gov.uk/publications/eOrderingDownload/DCSF_Child/Trafficking.pdf

Department for Children, Schools and Families. (2010). Working Together to Safeguard Children. London: Department for Children, Schools and Families. https://www.education.gov.uk/publications/eOrderingDownload/00305-2010DOM-EN.pdf

Department for Education. (2011). Child sexual exploitation Action Plan. London: Department of Education. https://www.education.gov.uk/publications/eOrderingDownload/DFE-00246-2011.pdf

Derby LSCB. (2010). Serious Case Review BD09. Derby: Derby LSCB. http://www.derbyscb.org.uk/docs/BD09SCRExecutiveSummary.pdf

Edwards, P. J., Roberts, I., Clarke, M. J., Diguiseppi, C., Wentz, R., Kwan, I., ... Pratap, S. (2009). Methods to increase response to postal and electronic questionnaires. Cochrane Database Systematic Reviews, Jul 8(3), MR000008. http://dx.doi.org/10.1002/14651858.MR000008.pub4

EPCAT. (2007). Missing Out - a study of child trafficking. London: ECPAT UK. http://www.ecpat.org.uk/sites/default/files/missing_out_2007.pdf

Gil, E. (1982). Institutional abuse of children in out-of-home care. In: R. Hanson (ed) Institutional Abuse of Children and Youth. New York: The Haworth Press.

The Guardian. (2011a, 8 January). White girls seen as 'easy meat' by Pakistani rapists, says Straw (p1). The Guardian.

The Guardian. (2011b, 12 January). Child sex abuse 'cannot be simplified along ethnic lines', says Ceop chief (p.18). The Guardian.

House of Commons Home Affairs Select Committee. (2009). The Trade in Human Beings - Human Trafficking in the UK. London: The Stationery Office.

http://www.publications.parliament.uk/pa/cm200809/cmselect/cmhaff/23/2302.htm

National Institute of Clinical Excellence. (2010). Promoting the quality of life of looked after children and young people - National Institute of Clinical Excellence Public Health Guidance 28. London: NIHCE and SCIE. http://publications.nice.org.uk/looked-after-children-and-young-people-ph28.

The Observer. (2011, 8 January). Too many of us treat young white women as trash (p.15). The Observer.

Rochdale LSCB. (2012). Review of Multi - agency Responses to the Sexual Exploitation of Children. Rochdale: Rochdale LSCB. http://www.rbscb.org/CSEReport.pdf

\section{(c) $)$ EY}

This work is licensed under a Creative Commons Attribution 3.0 License. 